\title{
Interaction of Pathogenic Vibrio Bacteria With the Blood Clot of the Pacific White Shrimp, Litopenaeus vannamei
}

\author{
VORRAPON CHAIKEERATISAK ${ }^{1,2,3}$, ANCHALEE TASSANAKAJON ${ }^{2}$, AND $^{2}$ \\ PETER B. ARMSTRONG ${ }^{3,4, *}$ \\ ${ }^{1}$ Division of Biological Sciences, University of California, San Diego, 9500 Gilman Drive, La Jolla, \\ California 92093; ${ }^{2}$ The Center of Excellence for Molecular Biology and Genomics of Shrimp, \\ Department of Biochemistry, Faculty of Science, Chulalongkorn University, Bangkok 10330, Thailand; \\ ${ }^{3}$ Department of Molecular and Cellular Biology, University of California, One Shields Avenue, Davis, \\ California 95616: ${ }^{4}$ Marine Biological Laboratory, 7 MBL Street, Woods Hole, Massachusetts 02543
}

\begin{abstract}
In addition to its roles in hemostasis and wound repair, the blood clot plays an underappreciated role in innate immunity, where the established clot serves as a barrier to microbial penetration into the internal milieu and where the early clot entraps and immobilizes microbes that have entered wounds to the integuments. In this report we document the behavior of the pathogenic gram-negative bacterium Vibrio harveyi that has been entrapped in the fabric of the extracellular blood clot of one of its target organisms, the Pacific white shrimp, Litopenaeus vannamei. The freshly entrapped bacteria are held tightly by the clot, losing even Brownian motility, but by $1 \mathrm{~h}$ post-entrapment, a fraction of the bacteria have established small domains of fibrinolysis that enlarge progressively, enabling bacteria to escape from the clot's embrace. Escape is dependent on the actions of both serine- and metallo-proteases released from the bacterial cells.
\end{abstract}

\section{Introduction}

Higher animals cope with invading pathogens by the activities of a variety of defense systems involving elements of the integuments and the extracellular matrix, specialized

\footnotetext{
* To whom correspondence should be addressed. E-mail: pbarmstrong@ucdavis.edu

Abbreviations: A2M, $\alpha_{2}$-macroglobulin; AEBSF, 4-(2-aminoethyl) benzenesulfonyl fluoride hydrochloride, a serine protease inhibitor; DIC, differential interference contrast microscopy; E-64, $N$-[N-(L-3-trans-carboxyirane-2-carbonyl)-L-leucyl]-agmatine, a cysteine protease inhibitor; SSS, sterile shrimp saline.
}

immune defense cells, and effector proteins and peptides that are found at the integumental surfaces and in the blood. The cellular and humoral components function to neutralize and clear the invading pathogens and the foreign molecules introduced by pathogens. The fibrillar extracellular blood clot is potentially an important element of the innate immune system. The clot can be a mechanical barrier to the entry of microbes through wounds to the integuments, can entrap and immobilize microbes that have entered the wound prior to the establishment of the mature clot (Bang, 1979; Dunn and Simmons, 1982; Rotstein, 1992; Isakova and Armstrong, 2003), can bind microbial toxins (Armstrong et al., 2013), and can activate a variety of other effector arms of the innate immune system (Opal and Esmon, 2003; Frick et al., 2006).

Pathogenic microbes show complex interactions with the fibrin clot of mammals and arthropods. They may provoke proteolytic lysis of the fibrin clot (see Armstrong, 2006; Sun, 2006) or they may induce formation of the clot (Bang, 1979; Persson et al., 2003). The fibrils of the extracellular blood clot of mammals and arthropods become decorated with several of the proteins of the innate immune system (Armstrong and Armstrong, 2003; Chaikeeratisak et al., 2012), suggesting that, in addition to the entrapment and binding of microbes, the clot may utilize this armament of immune effector proteins to play an active role in protecting the clot, in destroying entrapped microbes, and in sequestering and inactivating their toxic products.

The three taxa that have seen the best biochemical characterization of the clotting process are the vertebrates (Furie 
and Furie, 2000), the chelicerate arthropods (Muta and Iwanaga, 1996), and the crustaceans (Fuller and Doolittle, 1971a, b; Kopacek et al., 1993; Hall et al., 1999). In vertebrates and chelicerates, the initiation of the polymerization of the precursor structural protein into the fibrils of the clot involves the proteolytic activation of a soluble zymogen. The protolyzed zymogens, fibrin in vertebrates (Weisel, 2005) and coagulin in chelicerates (Kawasaki et al., 2000), assemble into the clot fibrils. The crustacean clot is established by the transglutaminase-catalyzed covalent cross-linking of an abundant plasma lipoprotein, variously named clotting protein $(\mathrm{CP})$ and very high density lipoprotein (VHDL) (Fuller and Doolittle, 1971a, b; Doolittle and Riley, 1990; Hall et al., 1999; Wang et al., 2001; Maningas et al., 2013).

The aquaculture of crustaceans has become an important sector of the agricultural economy in several parts of the world, with shrimp the mainstay of this industry (Leung and Engle, 2006). An important economic challenge to shrimp aquaculture is the susceptibility of shrimp to bacterial pathogens (Lavilla-Pitogo et al., 1998; Flegel, 2012). Vibrio harveyi is a serious pathogen in shrimp farming. Even though a detailed understanding of its pathogenic attack on shrimp remains elusive, its extracellular products, including proteases, phospholipases, and hemolysins, are believed to be the dominant virulent factors (Austin and Zhang, 2006).

In this report, we present the results of a study of the role of the shrimp blood clot in the defense against bacterial parasites. We use the gram-negative bacterium Vibrio harveyi as our test pathogen because it is responsible for major lost productivity for those species of crustaceans that are susceptible to infection; and we use the Pacific white shrimp, Litopenaeus vannamei, as the host species because its utility in aquaculture is limited by its susceptibility to Vibrio infection (Flegel, 2012).

\section{Materials and Methods}

\section{Animal cultivation}

Specific-pathogen-free (SPF) Pacific white shrimp, Litopenaeus vannamei Boone, 1931, were provided to us by Shaun M. Moss, Oceanic Institute, U.S. Marine Shrimp Farming Program, 41-202 Kalanianaole Hwy, Waimanalo, HI 96795-1820. The shrimp were acclimatized in artificial seawater with salinity of $30 \mathrm{ppt}$, ambient temperature, and continuous aeration for at least a week prior to use in experiments. Hemolymph was collected from the ventral cavity of the shrimp by aspiration into a 1-ml sterile syringe fitted with a 23-gauge syringe needle and was used immediately to set up the experimental situation before clotting had been initiated.

\section{Preparation of Vibrio harveyi strain 639}

The gram-negative bacterium $V$. harveyi, which is an important pathogen of aquacultured Pacific white shrimp, was cultured at $30{ }^{\circ} \mathrm{C}$ in stirred suspension culture in seawater complete culture medium (seawater, $750 \mathrm{ml}$; distilled water, $250 \mathrm{ml}$; Bacto tryptone, $5 \mathrm{~g}$; yeast extract, $1 \mathrm{~g}$; glycerol, $3 \mathrm{ml}$ ) and Difco Marine Broth 2216 (BD Bioscience) and was used when in log-phase growth. Bacteria that were added to shrimp hemolymph prior to the initiation of clotting were first washed free of culture medium by gentle centrifugation into sterile shrimp saline (SSS) $\left(15 \mathrm{mmol} \mathrm{l}^{-1}\right.$ $\mathrm{CaCl}_{2}, 7 \mathrm{mmol} \mathrm{l}^{-1} \mathrm{KCl}, 12.5 \mathrm{mmol} \mathrm{l}^{-1} \mathrm{MgCl}_{2} \cdot 6 \mathrm{H}_{2} \mathrm{O}, 7.4$ mmol l${ }^{-1} \mathrm{NaHCO}_{3}, 336 \mathrm{mmol} \mathrm{l}^{-1} \mathrm{NaCl}_{2}, \mathrm{pH}$ 7).

To produce "conditioned" bacterial culture medium, a clonal colony of bacteria grown on Difco Marine Agar 2216 (BD Bioscience) was transferred to $5 \mathrm{ml}$ of Difco Marine Broth 2216. The culture was incubated overnight on a rotary shaker at $30^{\circ} \mathrm{C}, 180$ rotations per min. Bacteria-conditioned culture medium was freed of bacterial cells by centrifugation at $16,000 \times g$ for $10 \mathrm{~min}$ and used immediately after preparation.

\section{Efficiency of bacterial entrapment by shrimp hemolymph clots}

Shrimp hemolymph collected without anticoagulant solution was heated to $55^{\circ} \mathrm{C}$ for $30 \mathrm{~min}$ to obtain unclottable hemolymph. Equal numbers of washed bacteria diluted in either SSS or unclottable hemolymph served as negative control groups. For the experimental group, the same numbers of $V$. harveyi were diluted in normal hemolymph; the sample was allowed to clot for $30 \mathrm{~min}$ at room temperature; and then the clot was removed, leaving clot-free serum. The concentrations of bacteria in control and serum preparations were determined by hemocytometer counts. Because the bacteria were motile, multiple digital photomicrographs were made of the hemocytometer with a Plan Neofluar 40/0.75 objective, and cell numbers were determined by counts made from the photomicrographs.

\section{Microscopic examination of the blood clot}

The method previously used for microscopic examination of the blood clot of the American horseshoe crab, Limulus polyphemus (Armstrong and Rickles, 1982), was adapted for the study of the shrimp clot. Shrimp plasma was collected without anticoagulant, and log-phase $V$. harveyi cells were prepared as described above. Pre-chilled shrimp hemolymph was spread as a thin layer on microscope coverglasses or mixed with a saline suspension of log-phase $V$. harveyi cells before being spread on a coverglass, which was then incubated at room temperature for $30 \mathrm{~min}$ in a moist chamber. The blood cells attached to the coverglass surface and the plasma positioned above the cells clotted in 
a few minutes. These preparations were then inverted above a volume of seawater complete bacteriological culture medium on a microscope slide. Small chips of microscope coverglass at the four corners of the slide supported the coverglass above the surface of the slide, and the preparation was sealed with a molten mixture of paraffin and beeswax painted around its perimeter. This system permitted extended observation of the blood clot with oil-immersion objectives with the light microscope. Fibrinolytic destruction of the clot was quantified by determining the fraction of entrapped bacteria that eventually established domains of fibrinolysis, as detected by a resumption of swimming motility and by the progressive enlargement of these fluid domains, as estimated by the maximum boundaries accessible to individual swimming bacteria. Five visual fields of a preparation were observed by phase contrast microscopy at $0,30,60,90$, and $120 \mathrm{~min}$ after initial bacterial entrapment, and the fraction of swimming bacteria was determined by comparing short photographic exposures and long exposures made at reduced illumination intensity obtained by inserting 0.5 - and 0.03-neutral density filters into the light path and optimizing exposure time for this reduced lighting intensity. Swimming bacteria presented as sharp images in the short exposures, but as blurred images in the long exposures, whereas immotile cells presented as sharp images in both the short- and long-exposure photomicrographs. To estimate the areas of clot fibrinolysis, single microscopic fields were video recorded for 1-min intervals at these same time points, and the areas of the clot traversed by individual swimming bacteria were traced from the video records. The planar areas accessible to the individual bacterial cells were calculated using the ImageJ program, ver. 1.47 (National Institutes of Health). Various protease inhibitors were included in the system to identify the classes of proteases involved in bacteria-mediated fibrinolysis.

\section{Fibrinolysis of the shrimp clot by Vibrio harveyi proteases}

Various protease inhibitors of known selectivity for their class-based protease inhibition capabilities were added to clots containing entrapped bacteria to identify the classes of proteases involved in bacteria-mediated fibrinolysis, with the expectation that inhibition of bacterial escape would identify the proteases that were necessary for clot fibrinolysis. In parallel, we investigated the ability of culture medium that had previously supported the growth of $V$. harveyi to degrade shrimp blood clots. The shrimp clots prepared on coverglasses as described above were incubated at $37^{\circ} \mathrm{C}$ for $3 \mathrm{~h}$ with Difco Marine Broth that had supported overnight growth of bacteria, and then were stained with GelCode Blue Stain Reagent (Pierce) to stain the clot protein that remained after treatment. Protease inhibitors were added to bacteria-conditioned culture medium to assist our identification of the classes of proteases that are required for fibrinolysis. Final concentrations of individual inhibitors are as followed; 1,10-phenanthroline, $2 \mathrm{mmol}^{-1}$; AEBSF, 1 mmol ${ }^{-1}$; E-64, $15 \mu \mathrm{mol} \mathrm{l}^{-1}$; and Pepstatin, $10 \mu \mathrm{mol} \mathrm{l}^{-1}$. For the top panel of Figure 5A, a 50- $\mu$ l drop of test medium was placed at the center of a uniform layer of clot. Clot fibrinolysis manifested as a central zone of loss of stained material. For the second panel of Figure 5A, a 5- $\mu 1$ sample of clot was positioned in the center of the field for each sample of the bottom panel and then submerged in a $0.5-\mathrm{ml}$ drop of test medium. Fibrinolysis was manifested as a reduced amount of stained protein in the 5 - $\mu$ l centrally positioned clot.

\section{Results}

\section{Bacterial entrapment by the shrimp blood clot}

The blood clot represents a potential barrier to entry to the internal milieu across wounds to the integument, both by capturing bacteria as the clot is forming and by physically blocking entry after clotting is complete. To estimate the entrapment efficiency of the developing blood clot of the shrimp, a fixed number of washed log-phase, free-swimming Vibrio harveyi cells were mixed with freshly drawn hemolymph, and the hemolymph was then allowed to clot (experimental sample). Controls involved parallel bacterial preparations suspended in sterile shrimp saline (SSS) or unclottable hemolymph $\left(55^{\circ} \mathrm{C}\right.$ heated plasma) (Fig. 1). The result revealed that approximately $84 \%$ of the $V$. harveyi cells were removed from suspension (entrapped in the clot or cytolysed) during the clotting process.

\section{Microscopic visualization of extracellular blood clots}

Microscopic observation of the shrimp blood clot allowed a study of the establishment of the clot and the fate of bacteria that had been captured by the clot. A thin layer of freshly collected, unclotted hemolymph, with or without added log-phase $V$. harveyi bacteria, was spread on a microscope coverglass and maintained at room temperature in a moist chamber to prevent drying. After clotting had occurred, this was mounted above a microscope slide for microscopic inspection. Although DIC microscopy visualized the blood cell secretory granules well, phase contrast microscopy was better in visualizing clot fibrils and bacteria entrapped in the clot. The blood cells attached to the surface of the coverglass. In decapods, the distinction is made between the hyaline cells, which are small and nearly agranular; the semi-granular cells, which are larger and whose cytoplasm contains smaller secretory granules; and the granular cells, which are larger still and contain an abundance of cytoplasmic secretory granules (Hose et al., 1990). The hyaline cells underwent cytolysis, leaving an 


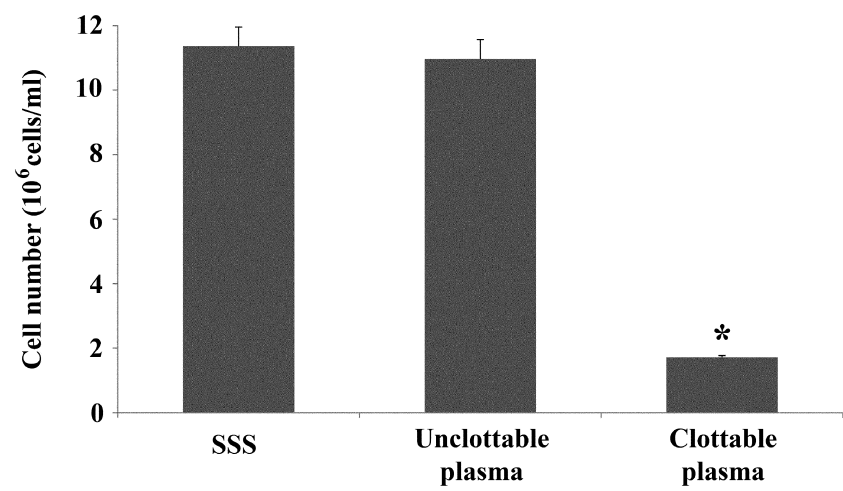

Figure 1. Capture of log-phase Vibrio harveyi by the blood clot of Litopenaeus vannamei. Control, sterile shrimp saline (SSS) and unclottable shrimp plasma; experimental, freshly drawn whole hemolymph. Three trials were done in each group. An asterisk represents a significant difference $(P<0.05)$ among the experimental groups.

intact-appearing nucleus (Fig. 2B and 2B'; white arrowheads). The semi-granular and granular cells remained intact and flattened on the glass surface (Fig. 2B). The plasma layer above the blood cells underwent clotting (Fig. 2B and 2B'; black arrowheads). It has been suggested that the cytolysis of the hyaline cells activates the blood clotting
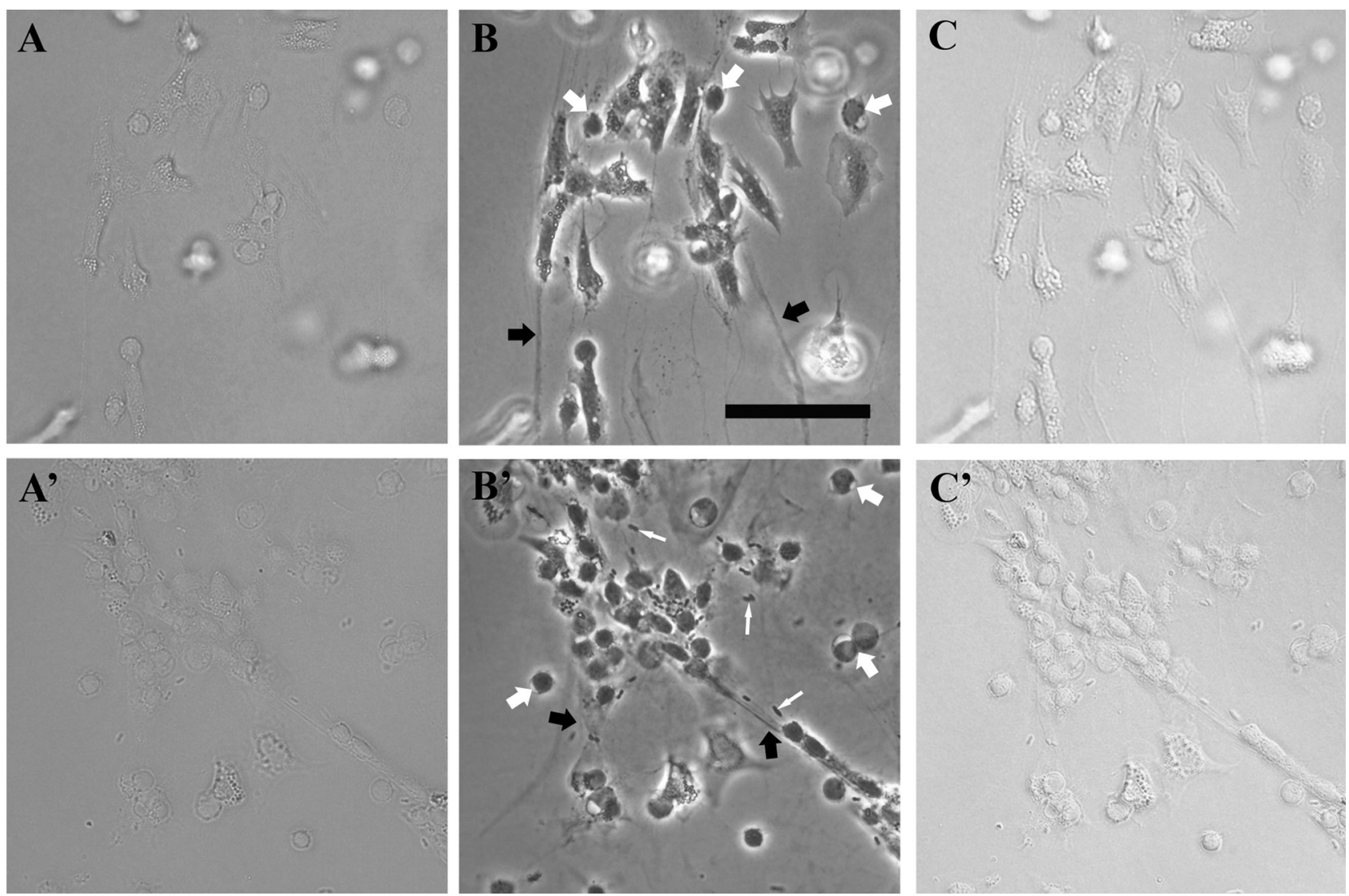

Figure 2. Structure of the shrimp blood clot with (A', B', C') and without (control, A, B, C) addition of Vibrio harveyi. (A, A') Bright-field microscopy; (B, B') phase contrast microscopy; (C, C') DIC microscopy. Black arrowheads indicate clot fibrils, and thick white arrowheads indicate cytolyzed hyaline cells. Bacterial cells, which can be seen as dark, rod-shape cells in B' (thin white arrows), were immobilized in the fabric of the clot. Micrographs represent at least three fields of view per sample. Scale bar, $50 \mu \mathrm{m}$. 
A)

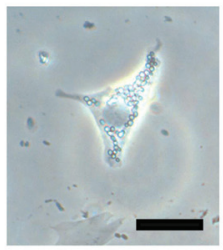

$0 \mathrm{~min}$

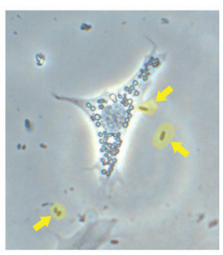

$30 \mathrm{~min}$

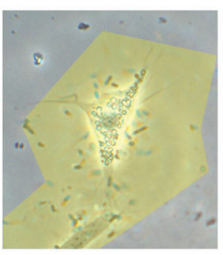

$60 \mathrm{~min}$

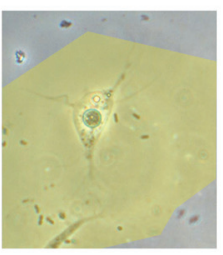

$90 \mathrm{~min}$

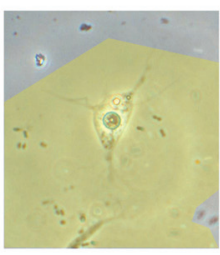

$120 \mathrm{~min}$

B)

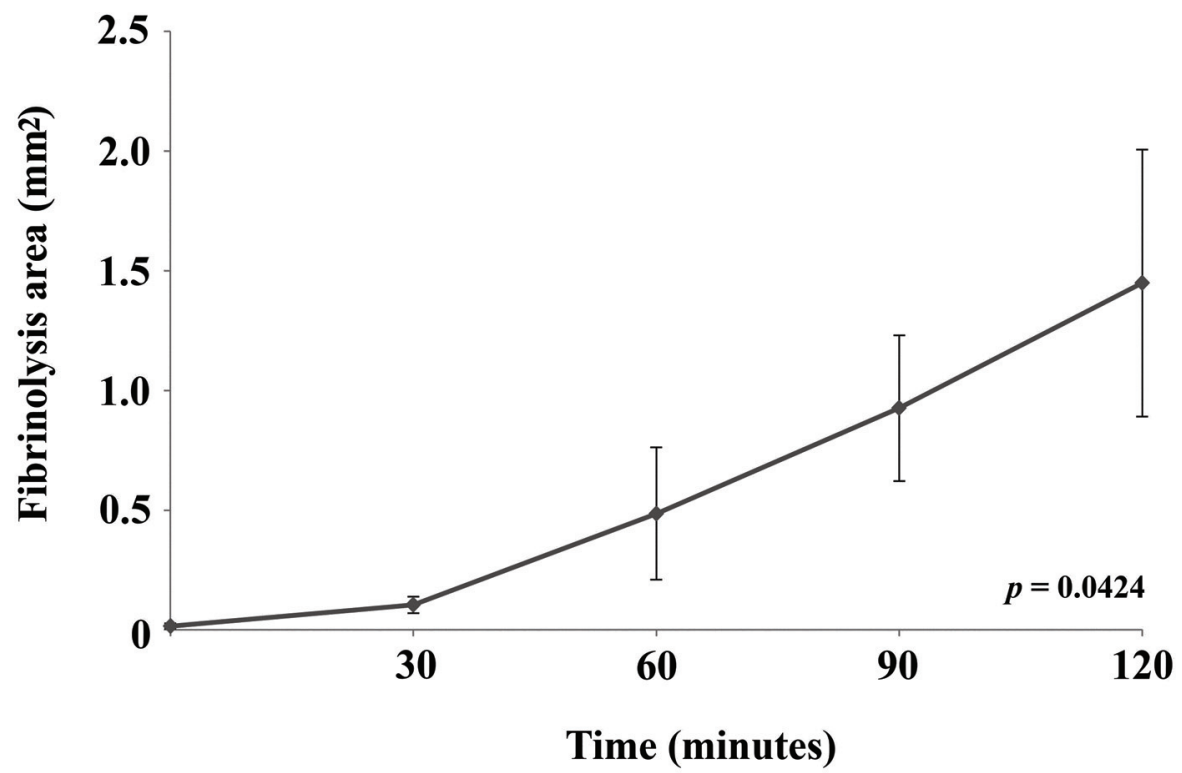

Figure 3. Escape of bacteria from confinement by the blood clot, as shown by restoration of swimming activity. (A) Photomicrographs of the same fields of blood clot taken every $30 \mathrm{~min}$ after initial clotting. Initially, the bacterial cells are held firmly, but by $30 \mathrm{~min}$ some of them have resumed swimming in small volumes of fluid (arrows) where the clot has been solubilized. Yellow overlays indicate the borders of the fluid chambers. These chambers enlarge over time, merging with one another starting at $60 \mathrm{~min}$ after clotting. By $120 \mathrm{~min}$, one-third of the bacteria were free of the clot. Scale bar, $20 \mu \mathrm{m}$. (B) Composite data obtained by measurement of the planar areas of fibrinolysis zones of three replicates. Error bars, \pm 1 S.E.M. (One-way ANOVA, $P<0.05$ ).

system because the earliest foci of clot formation coincide with these lysed cells (Hardy, 1892; Tait and Gunn, 1918). Bacteria added to the hemolymph prior to clotting became physically entrapped within fabric of the clot (thin white arrows, Fig. 2B'). We saw no evidence for cytolysis of the entrapped bacteria (data not shown), suggesting that the principal process for bacterial removal from the blood (Fig. 1) was physical entrapment by the clot.

\section{Vibrio harveyi is able to escape from the shrimp clot}

Most of the entrapped bacterial cells were initially completely immobilized: lacking their former active flagellumbased swimming locomotion and lacking even Brownian thermal motion. At later times, increasing numbers of the entrapped bacteria resumed their flagellar swimming in small fluid volumes that appeared within the clot and immediately surrounded each of the individual swimming cells (Fig. 3A; yellow overlays). By $2 \mathrm{~h}$, about a third of bacteria were seen swimming about in these little chambers. The sizes of the fluid chambers could be determined by tracing the motility of individual bacterial cells from video records $1 \mathrm{~min}$ in duration made at regular intervals from the same microscope field (Fig. 3A). With time, the volumes of each individual chamber surrounding the motile bacteria progressively enlarged, as revealed by progressively larger territories accessed by the individual swimming bacterial cells (Fig. 3B). Calculated by the ImageJ program, the fibrinolysis areas occurred in $V$. harveyi entrapping blood clots at $0,30,60,90$, and 120 min were $0.015,0.104,0.486,0.926$, and $1.448 \mathrm{~mm}^{2}$, respectively. The total area in the observed field is $7.237 \mathrm{~mm}^{2}$. Figure 3B shows an initially slow increase in the average area of fibrinolysis, followed by a period of exponential increase by $2 \mathrm{~h}$. When the edges of an ever-enlarging volume of fibrinolysis reached the surface of the clot, the bacterium was able to escape from the clot into the surrounding environment. 


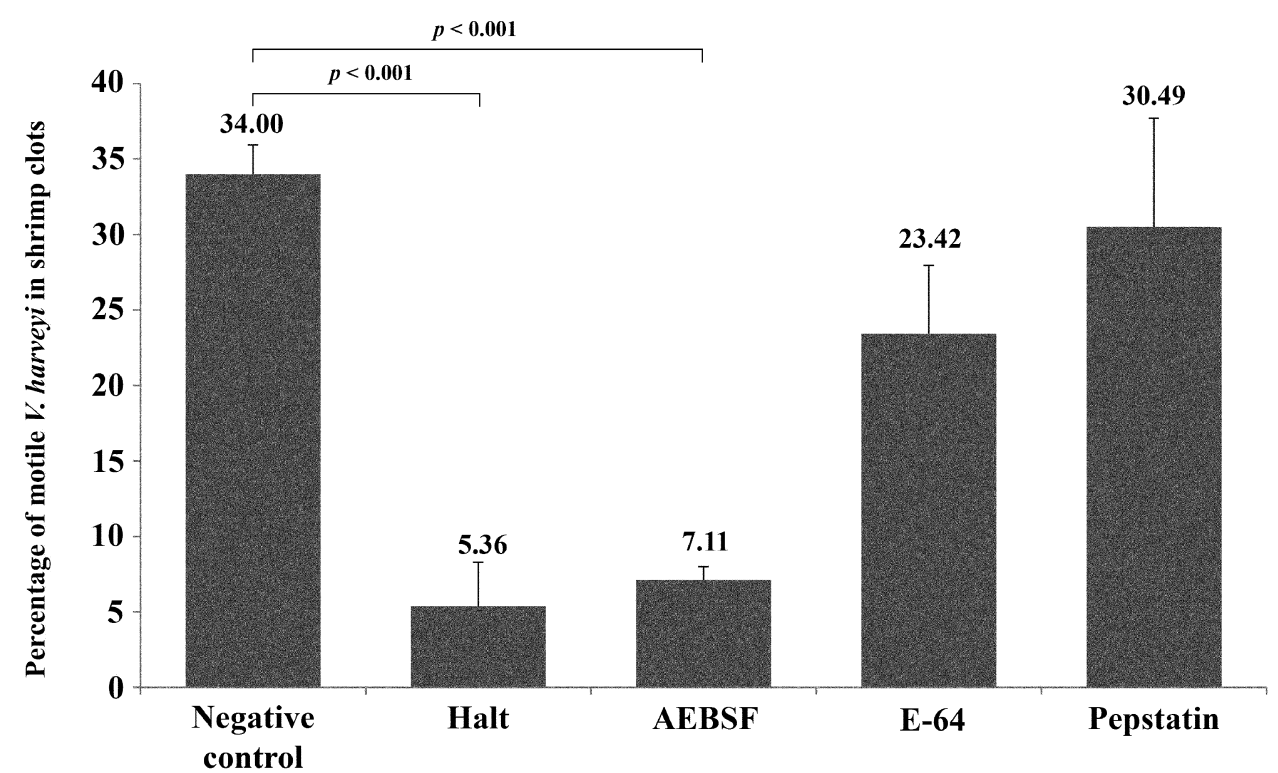

Protease inhibitors added conditions

Figure 4. Effect of protease inhibitors on the entrapment of Vibrio harveyi cells in the clot at $2 \mathrm{~h}$. Control, no inhibitors; Halt, $1 \times$ Halt Protease Inhibitor Cocktail; AEBSF, a serine protease inhibitor; E-64, a cysteine protease inhibitor; pepstatin, an aspartyl protease inhibitor. Only HALT and AEBSF significantly suppressed bacterial escape from the clot.

Both serine- and metalloproteases released from Vibrio harveyi cells are required for fibrinolysis

Vibrio-mediated fibrinolysis was dependent on proteolytic destruction of the fabric of the clot. The effect of protease inhibitors on bacterial escape was assessed by the suppression of the reestablishment of active swimming motility at $2 \mathrm{~h}$ after initial entrapment. Fibrinolysis was suppressed by the inclusion of the Halt Protease Inhibitor Cocktail (Thermo Scientific Cat 1860932) diluted 100-fold to the standard working concentration. This mixture of protease inhibitors contains the serine protease inhibitors $\operatorname{AEBSF}\left(1 \mathrm{mmol} \mathrm{l}^{-1}\right)$ and aprotinin $\left(0.8 \mathrm{mmol} \mathrm{l}^{-1}\right)$; the amino-peptidase inhibitor bestatin $\left(50 \mu \mathrm{mol} \mathrm{l}^{-1}\right)$; the cysteine protease inhibitor E-64 $\left(15 \mu \mathrm{mol} \mathrm{l}^{-1}\right)$; the broadspectrum protease inhibitor leupeptin $\left(20 \mu \mathrm{mol}^{-1}\right)$; and the aspartyl protease inhibitor pepstatin A $\left(10 \mu \mathrm{mol} \mathrm{l}^{-1}\right)$. Because this cocktail of inhibitors did not affect the active swimming motility of $V$. harveyi cells maintained in suspension culture, the inhibition of bacterial escape is independent of cytotoxic effects. Because $1 \mathrm{mmol} \mathrm{l}^{-1}$ AEBSF alone suppressed bacterial escape (Fig. 4), it is suggested that serine proteases are necessary for bacterial-mediated fibrinolysis. Bacteria-derived metalloproteases appear to also be required because fibrinolysis is suppressed by the inclusion of $2 \mathrm{mmol} \mathrm{l}^{-1} 1,10$-phenanthroline in the absence of other inhibitors. The inhibitors E-64 and pepstatin fail to suppress fibrinolysis (Fig. 5A). This suggests that both bacterial serine- and metallo-proteases are required for fi- brinolytic attack on the shrimp blood clot and that cysteineand aspartyl-proteases are not required for fibrinolysis. The arthropod blood clot is extensively cross linked by intermolecular $\mathrm{N}^{\varepsilon}(\gamma$-glutamyl)lysine side chain cross links, which may confer a sufficient resistance to proteolytic attack, thereby necessitating the synergistic actions of both serineand metallo-proteases for successful fibrinolysis by the suite of proteases that are secreted by $V$. harveyi.

In addition to the fibrinolytic effects of bacterial secretions, the shrimp blood cells that attach to the glass substratum of the observation chambers suffer morphological disfigurement when adjacent to the clot-entrapped bacteria (Fig. 5B; arrows). This might be due to a protease-mediated reduction of adhesiveness of the blood cells from the glass surface or might be a response to cytotoxic agents released from the bacterial cells.

\section{Discussion}

The principal imperative for all organisms is to reproduce and transmit their genes to the next generation. Parasitism, and the attendant disease and premature death, is an important impediment to this imperative. A first line of defense is the integument that isolates the internal milieu of metazoans from the external environment. The immune system, with its ability to eliminate and sequester pathogens and their toxic products from the surfaces of the integuments and from the internal milieu, is the second line of defense.

One of the first defense systems that parasites encounter 
A)
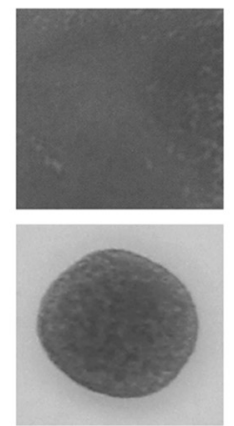

Negative control
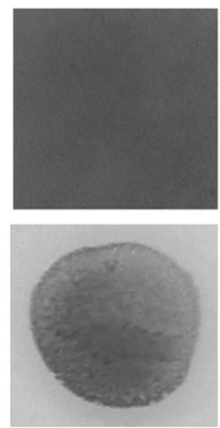

Mix
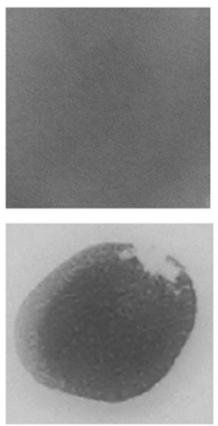

1,10-Phenan throline
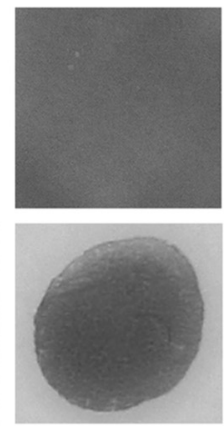

AEBSF
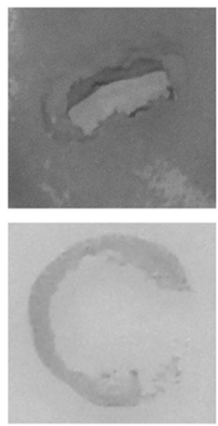

E-64
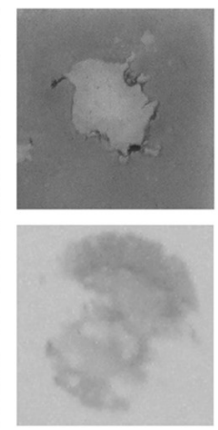

Pepstatin
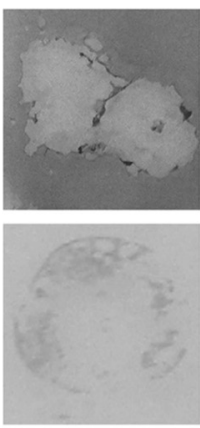

Positive control
B) Negative control
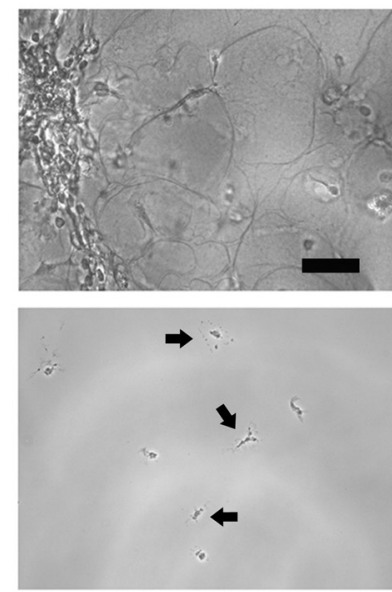

E-64
Mix
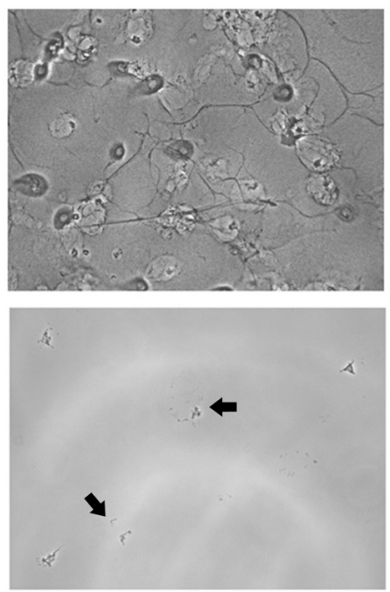

Pepstatin
1,10-Phenanthroline
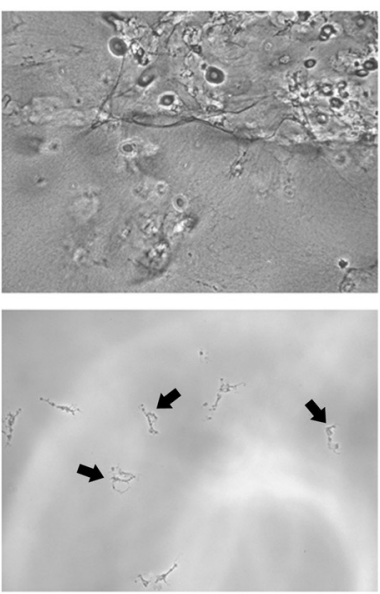

Positive control

Figure 5. Protease-based fibrinolysis of the shrimp blood clot. Degradation of the clot by Vibrio-conditioned culture medium was inhibited by MIX ( $1 \times$ Halt Protease Inhibitor Cocktail supplemented with 1,10-phenanthroline); by 1,10-phenanthroline (a metallo-protease inhibitor); and by AEBSF (a serine protease inhibitor); but not by E-64 (a cysteine protease inhibitor), pepstatin A (an aspartyl protease inhibitor), or the positive control (no protease inhibitors). Negative control, sterile Difco Marine Broth 2216). Images are representative of three independent trials. (A: Top panel) A 50- $\mu$ l drop of test medium was placed at the center of a uniform layer of clot. (A: Lower panel) A 5- $\mu$ l sample of clot was positioned in the center of the field for each trial and was then submerged in a 0.5 -ml drop of test medium. (B) Phase contrast micrographs of clots stained with GelCode Blue Stain Reagent (Pierce). Arrows indicate morphologically deformed blood cells next to the entrapped bacteria. Scale bar, $50 \mu \mathrm{m}$.

after successful penetration of the integuments of metazoans is the extracellular blood clotting system. The fibrin clot in vertebrates, the coagulin clot of chelicerate arthropods, and the extracellular clot of crustaceans, established by the transglutaminase-mediated covalent crosslinking of an abundant plasma protein, variously identified as "clotting protein" (CP) or "very high-density lipoprotein" (VHDL), represent well-characterized examples of the extracellular matrix that is formed at wound sites. These clots function to staunch bleeding, as a substrate for invasion of woundhealing tissue cells, and as an arm of the innate immune system. In this capacity, the fully established clot, like the intact integuments, presents a mechanical barrier to penetration into the internal milieu. As demonstrated by the present study, the extracellular clot entraps microbes during its establishment at wound sites. Suppression of the blood clotting system rendered shrimp more susceptible to viral and bacterial infection, consistent with the notion that the blood clotting system is essential to immunity (Maningas et al., 2008). Entrapment of the virulent pathogen Vibrio harveyi is relatively short-lived. A significant fraction of the entrapped bacterial cells secrete sufficient quantities of 
fibrinolytic proteases to overwhelm the protective actions of the protease-binding protein, $\alpha_{2}$-macroglobulin (A2M), which binds to the clot fibrils during clot formation and slows their degradation by fibrinolytic proteases (Chaikeeratisak et al., 2012). But eventually, even isolated bacteria entrapped in the clot secrete sufficient quantities of proteases to swamp the protective actions of $\mathrm{A} 2 \mathrm{M}$, and fibrinolytic degradation can begin.

It is suggested that the fibrinolytic proteases of $V$. harveyi operate as a suite of virulence factors that play an important role in establishing the successful infection of the shrimp host. This proposal could be investigated by comparing the infectivity and pathologic potential of wild-type strains of $V$. harveyi with strains that lack one or more of the essential fibrinolytic enzymes. The experimental literature contains several examples of bacterial parasites of mammals in which fibrinolytic proteases play an essential role in virulence ( reviewed in Armstrong, 2001, 2006).

To date, several extracellular proteases belonging to $V$. harveyi have been identified: a $22-\mathrm{kDa}$ cysteine protease, which is an important exotoxin (Liu et al., 1997; Liu and Lee, 1999), and three alkaline metal-chelator-sensitive proteases (Fukasawa et al., 1988a, b). Other species of Vibrio have been found to secrete serine (Park et al., 2009) and metalloproteases (Chang et al., 2005; Kwon et al., 2007) with fibrinolytic activities to proteins of the human clotting system. To our knowledge, this present study is the first to report a similar situation in arthropods in which an arthropod pathogen is allowed to interact with an arthropod blood clot. It is interesting in the present system that the synergistic actions of both serine- and metallo-proteases are required for successful proteolytic destruction of the shrimp clot.

\section{Acknowledgments}

This research was financially supported by a student fellowship for Vorrapon Chaikeeratisak from the Royal Golden Jubilee Ph.D. program under the Thailand Research Fund (TRF) and by grant 0344360 from the National Science Foundation (PBA). We thank Dr. Kunlaya Somboonwiwat for her careful reading of the manuscript and Poochit Nonejuie for his help with the statistical analysis of data. We also thank Shaun M. Moss, Oceanic Institute, U.S. Marine Shrimp Farming Program, for his kindly offer to supply the experimental shrimp used in our study.

\section{Literature Cited}

Armstrong, P. B. 2001. The contribution of proteinase inhibitors to immune defense. Trends Immunol. 22: 47-52.

Armstrong, P. B. 2006. Proteases and protease inhibitors: a balance of activities in host-pathogen interaction. Immunobiology 211: 263-281.

Armstrong, P. B., and M. T. Armstrong. 2003. The decorated clot: binding of agents of the innate immune system to the fibrils of the Limulus blood clot. Biol. Bull. 205: 201-203.
Armstrong, P. B., and F. R. Rickles. 1982. Endotoxin-induced degranulation of the Limulus amebocyte. Exp. Cell Res. 140: 15-24.

Armstrong, M. T., F. R. Rickles, and P. B. Armstrong. 2013. Capture of lipopolysaccharide (endotoxin) by the blood clot: a comparative study. PloS ONE 8: e80192.

Austin, B., and X. H. Zhang. 2006. Vibrio harveyi: a significant pathogen of marine vertebrates and invertebrates. Lett. Appl. Microbiol. 43: 119-124.

Bang, F. B. 1979. Ontogeny and phylogeny of response to gram-negative endotoxins among the marine invertebrates. Pp. 109-123 in Biomedical Applications of the Horseshoe Crab (Limulidae), E. Cohen, F. B. Bang, J. Levin, J. J. Marchalonis, T. G. Pistole, R. A. Prendergast, C. Shuster, and S. W. Watson, eds. Alan R. Liss, New York.

Chaikeeratisak, V., K. Somboonwiwat, and A. Tassanakajon. 2012. Shrimp alpha-2-macroglobulin prevents the bacterial escape by inhibiting fibrinolysis of blood clots. PloS ONE 7: e47384.

Chang, A. K., H. Y. Kim, J. E. Park, P. Acharya, I. S. Park, S. M. Yoon, H. J. You, K. S. Hahm, J. K. Park, and J. S. Lee. 2005. Vibrio vulnificus secretes a broad-specificity metalloprotease capable of interfering with blood homeostasis through prothrombin activation and fibrinolysis. J. Bacteriol. 187: 6909-6916.

Doolittle, R. F., and M. Riley. 1990. The amino-terminal sequence of lobster fibrinogen reveals common ancestry with vitellogenins. Biochem. Biophys. Res. Commun. 167: 16-19.

Dunn, D. L., and R. L. Simmons. 1982. Fibrin in peritonitis. III. The mechanism of bacterial trapping by polymerizing fibrin. Surgery 92: 513-519.

Flegel, T. W. 2012. Historic emergence, impact and current status of shrimp pathogens in Asia. J. Invertebr. Pathol. 110: 166-173.

Frick, I. M., P. Akesson, H. Herwald, M. Mörgelin, M. Malmsten, D. K. Nägler, and L. Björck. 2006. The contact system-a novel branch of innate immunity generating antibacterial peptides. EMBO J. 25: $5569-5578$.

Fukasawa, S., K. Nakamura, A. Kamii, Y. Ohyama, and M. Osumi. 1988a. Purification and properties of a proteinase from a marine luminous bacterium, Vibrio harveyi strain FLA-11. Agric. Biol. Chem. 52: $435-441$.

Fukasawa, S., K. Nakamura, M. Miyahira, and M. Kurata. 1988b. Some properties of two proteinases from a luminous bacterium, Vibrio harveyi strain FLN-108. Agric. Biol. Chem. 52: 3009-3014.

Fuller, G. M., and R. F. Doolittle. 1971a. Studies of invertebrate fibrinogen. I. Purification and characterization of fibrinogen from the spiny lobster. Biochemistry 10: 1305-1311.

Fuller, G. M., and R. F. Doolittle. 1971b. Studies of invertebrate fibrinogen. II. Transformation of lobster fibrinogen into fibrin. Biochemistry 10: 1311-1315.

Furie, B., and B. Furie. 2000. Molecular basis of blood coagulation. Pp. 1783-1804 in Hematology: Basic Principles and Practice, R. Hoffman, E. J. Benz, S. J. Shattil, B. Furie, H. J. Cohen, L. E. Silberstein, and P. McGlave, eds. Churchill Livingstone, New York.

Hall, M., R. Wang, R. van Antwerpen, L. Sottrup-Jensen, and K. Söderhäll. 1999. The crayfish plasma clotting protein: a vitellogeninrelated protein responsible for clot formation in crustacean blood. Proc. Natl. Acad. Sci. USA 96: 1965-1970.

Hardy, W. B. 1892. The blood corpuscles of the crustacea, together with a suggestion as to the origin of the crustacean fibrin-ferment. J. Physiol 13: $165-190$.

Hose, J. E., G. G. Martin, and A. S. Gerard. 1990. A decapod hemocyte classification scheme integrating morphology, cytochemistry, and function. Biol. Bull. 178: 33-45.

Isakova, V., and P. B. Armstrong. 2003. Imprisonment in a death-row cell: the fates of microbes entrapped in the Limulus blood clot. Biol. Bull. 205: 203-204.

Kawasaki, H., T. Nose, T. Muta, S. Iwanaga, Y. Shimohigashi, and S. 
Kawabata. 2000. Head-to-tail polymerization of coagulin, a clottable protein of the horseshoe crab. J. Biol. Chem. 275: 35297-35301.

Kopacek, P., M. Hall, and K. Söderhäll. 1993. Characterization of a clotting protein, isolated from plasma of the freshwater crayfish Pacifastacus leniusculus. Eur. J Biochem. 213: 591-597.

Kwon, J. Y., A. K. Chang, J. E. Park, S. Y. Shin, S. M. Yoon, and J. S. Lee. 2007. Vibrio extracellular protease with prothrombin activation and fibrinolytic activities. Int. J. Mol. Med. 19: 157-163.

Lavilla-Pitogo, C. R., E. M. Leano, and M. G. Paner. 1998. Mortalities of pond-cultured juvenile shrimp, Penaeus monodon, associated with dominance of luminescent vibrios in the rearing environment. Aquaculture 164: 337-349.

Leung, P. S., and C. R. Engle. 2006. Shrimp Culture: Economics, Market, and Trade. Wiley-Blackwell, Hoboken, NJ.

Liu, P. C., and K. K. Lee. 1999. Cysteine protease is a major exotoxin of pathogenic luminous Vibrio harveyi in the tiger prawn, Penaeus monodon. Lett. Appl. Microbiol. 28: 428-430.

Liu, P. C., K. K. Lee, C. C. Tu, and S. N. Chen. 1997. Purification and characterization of a cysteine protease produced by pathogenic luminous Vibrio harveyi. Curr. Microbiol. 35: 32-39.

Maningas, M. B., H. Kondo, I. Hirono, T. Saito-Taki, and T. Aoki. 2008. Essential function of transglutaminase and clotting protein in shrimp immunity. Mol. Immunol. 45: 1269-1275.

Maningas, M. B., H. Kondo, and I. Hirono. 2013. Molecular mechanisms of the shrimp clotting system. Fish Shellfish Immunol. 34: 968-972.
Muta, T., and S. Iwanaga. 1996. Clotting and immune defense in Limulidae. Prog. Mol. Subcell. Biol. 15: 154-189.

Opal, S. M., and C. T. Esmon. 2003. Bench-to-bedside review: functional relationships between coagulation and the innate immune response and their respective roles in the pathogenesis of sepsis. Crit. Care 7: 23-38.

Park, B. S., D. H. Song, H. M. Kim, B. S. Choi, H. Lee, and J. O. Lee. 2009. The structural basis of lipopolysaccharide recognition by the TLR4-MD-2 complex. Nature 458: 1191-1195.

Persson, K., W. Russell, M. Morgelin, and H. Herwald. 2003. The conversion of fibrinogen to fibrin at the surface of curliated Escherichia coli bacteria leads to the generation of proinflammatory fibrinopeptides. J. Biol. Chem. 278: 31884-31890.

Rotstein, O. D. 1992. Role of fibrin deposition in the pathogenesis of intraabdominal infection. Eur. J. Clin. Microbiol. Infect. Dis. 11: $1064-1068$.

Sun, H. 2006. The interaction between pathogens and the host coagulation system. Physiology (Bethesda) 21: 281-288.

Tait, J., and J. D. Gunn. 1918. The blood of Astacus fluviatilis: a study in crustacean blood, with special reference to coagulation and phagocytosis. Q. J. Exp. Physiol. 12: 35-80.

Wang, R., Z. Liang, M. Hal, and K. Söderhäll. 2001. A transglutaminase involved in the coagulation system of the freshwater crayfish, Pacifastacus leniusculus. Tissue localisation and cDNA cloning. Fish Shellfish Immunol. 11: 623-637.

Weisel, J. W. 2005. Fibrinogen and fibrin. Adv. Protein Chem. 70: 247-299. 